Research Paper

\title{
The association of RAN and RANBP2 gene polymer- phisms with Wilms tumor risk in Chinese children
}

\author{
Xiaokai Huang ${ }^{1 *}$, Jie Zhao ${ }^{1 *}$, Wen $\mathrm{Fu}^{2 *}$, Jinhong $\mathrm{Zhu}^{3}$, Susu Lou ${ }^{1}$, Xiaoqian Tian ${ }^{1}$, Shanshan Chen ${ }^{1}$, Jichen \\ Ruan', Jing $\mathrm{He}^{1,2 \bowtie}$, Haixia Zhou ${ }^{1 \bowtie}$ \\ 1. Department of Hematology, The Second Affiliated Hospital and Yuying Children's Hospital of Wenzhou Medical University, Wenzhou 325027, Zhejiang, \\ China \\ 2. Department of Pediatric Surgery, Guangzhou Institute of Pediatrics, Guangzhou Women and Children's Medical Center, Guangzhou Medical University, \\ Guangzhou, Guangdong 510623, China \\ 3. Department of Clinical Laboratory, Biobank, Harbin Medical University Cancer Hospital, Harbin 150040, Heilongjiang, China
}

"These authors contribute equally to this work.

$\triangle$ Corresponding authors: Haixia Zhou, Department of Hematology, The Second Affiliated Hospital and Yuying Children's Hospital of Wenzhou Medical University, 109 West Xueyuan Road, Wenzhou 325027, Zhejiang, China, Tel./Fax: +86-13587898900, Email: zhxcrystal@126.com; or Jing He, Department of Pediatric Surgery, Guangzhou Institute of Pediatrics, Guangzhou Women and Children's Medical Center, Guangzhou Medical University, 9 Jinsui Road, Guangzhou 510623, Guangdong, China, Tel./Fax: (+86-020)38076560, Email: hejing@gwcmc.org.

(1) The author(s). This is an open access article distributed under the terms of the Creative Commons Attribution License (https://creativecommons.org/licenses/by/4.0/). See http://ivyspring.com/terms for full terms and conditions.

Received: 2019.05.11; Accepted: 2019.11.03; Published: 2020.01.01

\begin{abstract}
Wilms tumor is considered to be the most common renal malignancy among children. RAN, a member of RAS superfamily, and its binding partner RANBP2 are related to the progression of multiple tumors. Nevertheless, the effects of the RAN and RANBP2 gene polymorphisms on the tumorigenesis of Wilms tumor remain unclarified. In this study, three potentially functional polymorphisms (rs56109543 C>T, rs7132224 A>G, and rs14035 C>T) in the RAN and one ( $r$ s2462788 C>T) in the RANBP2 were chosen to investigate their association with Wilms tumor susceptibility. Odds ratios (ORs) and $95 \%$ confidence intervals $(\mathrm{Cls})$ were applied to assess the association of the selected polymorphisms with Wilms tumor susceptibility. Results shown that RAN rs7132224 AG/GG genotypes significantly increased Wilms tumor risk when compared to AA genotype (adjusted $\mathrm{OR}=1.40,95 \% \mathrm{Cl}=1.01-1.95, P=0.047$ ). Carriers of $1-3$ risk genotypes have a significantly higher Wilms tumor risk than those without risk genotype (adjusted OR=1.49, 95\% $\mathrm{Cl}=1.07-2.07, P=0.020$ ). Moreover, stratified analysis indicated that $R A N$ rs56109543 CT/TT genotypes, RAN rs7132224 AG/GG genotypes and RANBP2 rs2462788 CT/TT genotypes remarkably increased Wilms tumor susceptibility among the subgroups. Our results indicated that RAN and RANBP2 polymorphisms were associated with Wilms tumor susceptibility in Chinese children. The role of RAN/RANBP2 in cancers deserves more attention.
\end{abstract}

Key words: RAN, RANBP2, polymorphism, Wilms tumor, susceptibility

\section{Introduction}

Wilms tumor, resulting from deviant cellular proliferation and differentiation, is currently one of the most concerned tumors in children [1, 2]. It is also one of the most common solid pediatric tumors, especially before the age of five years [3]. This tumor affects 1 in 10000 children and constitutes $8 \%$ of pediatric cancers [4]. Although Wilms tumor have an overall survival rate of $80 \%$, more than $15 \%$ of patients have a poor prognosis despite aggressive retreatment [5]. The patients with anaplastic Wilms tumor, relapsed and blastemal-type disease have a very low survival rate [6]. Therefore, it is indispensable to find more effective therapies in order to improve the poor prognosis of Wilms tumor.

In recent years, it is gradually recognized that the occurrence and development of Wilms tumor is closely connected to various genetic alterations [7]. For instance, aberrant splicing of WT1, a pivotal 
cancer suppressor gene, increased the risk of Wilms tumor [8]. MYCN amplification enhances promoted the development of Wilms tumor through multiple mechanisms [9]. Moreover, numerous gene polymorphisms have been found to predispose to Wilms tumor [10-12], including WTX [13], P53 [14], CTNNB1 [15], BARD1 [16], HACE1 [17], LIN28B [18], XPD [19], hOGG1 and FEN1 gene [20], KRAS [21]. Although quite a few of predisposing genetic factors have been found, they are far from enough to explicitly explain the genetic pathogenesis of Wilms tumor.

RAN, belonging to RAS superfamily, is a small GTP-binding protein, which is composed of 216 amino acids with typical sequence motifs. Previous experiments have demonstrated that RAN was closely related to mitotic process, nucleo-cytoplasmic transport, nuclear transport of proteins, and the formation of nuclear envelope [22-24]. RAN is regarded as a decisive molecular switch for chromosome arrangement and mitotic progression. When nucleotide-free RAN binds to Mog1, not only is anaphase of mitosis delayed, but also many mitotic defects appeared [25]. RANBP2, recognized as a pleiotropic protein, plays physiological roles in reconciling gene-environment interactions. It consists of several domains, including four RAN-binding domains [26]. Both RAN and RANBP2 are involved in mitosis and are associated with a variety of cancers. Thus, we conducted this study to examine the association of RAN and RANBP2 gene polymorphisms with Wilms tumor risk as well as cumulative effects of polymorphisms in the two genes.

\section{Materials and methods}

\section{Study subjects}

This study was authorized by the Institutional Review Board of Guangzhou Women and Children's Medical Center and Yuying Children's Hospital of Wenzhou Medical University. Written informed consents were obtained from all participants signed by their guardians. In this retrospective research, 183 patients diagnosed with Wilms tumor and 603 cancer-free volunteers were recruited (Supplementary Table 1). All the included patients were newly diagnosed and had histopathologically verified Wilms tumor. The exclusion criteria included prior chemotherapy or radiation, other types of tumors, and secondary or recurrent tumors. Controls were recruited from children receiving regular physical examination int the designated hospitals during the same period. Age and sex were matched between cases and controls. Both the cases and controls were unrelated ethnic Chinese Han individuals.

\section{Polymorphisms selection and genotyping}

Three potentially functional polymorphisms in the RAN (rs56109543 C>T, rs7132224 A>G, rs14035 $\mathrm{C}>\mathrm{T}$ ) and one potentially functional polymorphism in the RANBP2 (rs2462788 C>T) were chosen in this study. The criteria of SNPs selection and genotyping have been described in our previous study [27].

\section{Statistical analysis}

Chi-squared test was used to compare the demographic variables and the frequency distribution of gene polymorphisms between cases and controls. The goodness-of-fit $\chi^{2}$ test was used to estimate the Hardy-Weinberg equilibrium (HWE) in control subjects. Univariate and multivariate logistic regression analyses were conducted. Odds ratios (ORs) and 95\% confidence intervals (CIs) were used to assess the association of RAN/RANBP2 gene polymorphisms with Wilms tumor susceptibility. All of the statistical tests adopted bilateral. Results were recognized as statistically significant if $P<0.05$.

\section{Results}

\section{Associations between RAN/RANBP2 polymorphisms and Wilms tumor risk}

The whole genotype frequencies of polymorphisms in the RAN and RANBP2 gene were outlined in Table 1. It is apparently that rs7132224 AG/GG genotypes carriers were associated with an increased risk of Wilms tumor when compared with AA genotype carriers (adjusted OR=1.40, 95\% $\mathrm{CI}=1.01-1.95, \quad P=0.047)$. However, no significant association was detected between the other three polymorphisms and Wilms tumor susceptibility. Furthermore, higher risk was demonstrated in participants with 1-3 risk genotypes (adjusted $\mathrm{OR}=1.49,95 \% \mathrm{CI}=1.07-2.07, P=0.020$ ) when compared with those without risk genotype.

\section{Stratified analysis}

As shown in Table 2 and Table 3, the RAN rs56109543 CT/TT genotypes (adjusted OR=1.98, 95\% $\mathrm{CI}=1.15-3.38, P=0.013)$ and $R A N$ rs7132224 AG/GG genotypes (adjusted $\mathrm{OR}=2.80,95 \% \mathrm{CI}=1.64-4.77$, $P=0.0002$ ) increased the risk of Wilms tumor among the children aged $\leq 18$ months. The presence of $1-3$ risk genotypes have an increased risk of Wilms tumor in children aged $\leq 18$ months (adjusted OR $=2.80,95 \%$ $\mathrm{CI}=1.64-4.77, P=0.0002$ ) and male (adjusted $\mathrm{OR}=1.57$, 95\% CI=1.01-2.46, $P=0.046)$ when compared with those without risk genotype. In addition, the RANBP2 gene rs2462788 CT/TT conferred the susceptibility to Wilms tumor in children aged $\leq 18$ months (adjusted 
$\mathrm{OR}=2.43,95 \% \mathrm{CI}=1.15-5.12, P=0.020$ ), male (adjusted $\mathrm{OR}=2.15,95 \% \mathrm{CI}=1.08-4.25, P=0.029)$ and subgroup with clinical stage I+II Wilms tumor (adjusted $\mathrm{OR}=2.77,95 \% \mathrm{CI}=1.41-5.46, P=0.003)$.

\section{Haplotype analysis}

As presented in Table 4, compared to haplotype
TTT, the following four haplotypes significant increased the risk of Wilms tumor: TTC (adjusted $\mathrm{OR}=22.58, \quad 95 \% \quad \mathrm{CI}=2.68-190.04, \quad P=0.004), \quad \mathrm{TCT}$ (adjusted $\mathrm{OR}=1.56,95 \% \mathrm{CI}=1.04-2.34, P=0.031$ ), CCT (adjusted $\mathrm{OR}=15.22,95 \% \mathrm{CI}=1.69-136.97, P=0.015$ ) and CCC (adjusted OR=1.46, 95\% CI=1.09-1.97, $P=0.012$ ).

Table 1. Association between RAN/RANBP2 gene polymorphisms and Wilms tumor susceptibility

\begin{tabular}{|c|c|c|c|c|c|c|c|}
\hline Genotype & $\begin{array}{l}\text { Cases } \\
(\mathrm{N}=183)\end{array}$ & $\begin{array}{l}\text { Controls } \\
(\mathrm{N}=603)\end{array}$ & $P$ a & $\begin{array}{l}\text { Crude OR } \\
(95 \% \text { CI })\end{array}$ & $P$ & $\begin{array}{l}\text { Adjusted OR } \\
(95 \% \text { CI })^{b}\end{array}$ & $P^{b}$ \\
\hline \multicolumn{8}{|c|}{$R A N$ rs56109543 C>T (HWE $=0.258)$} \\
\hline $\mathrm{CC}$ & $117(63.93)$ & $430(71.31)$ & & 1.00 & & 1.00 & \\
\hline $\mathrm{CT}$ & $59(32.24)$ & $154(25.54)$ & & $1.41(0.98-2.02)$ & 0.065 & $1.41(0.98-2.02)$ & 0.065 \\
\hline TT & $7(3.83)$ & $19(3.15)$ & & $1.35(0.56-3.30)$ & 0.505 & $1.35(0.56-3.30)$ & 0.504 \\
\hline Additive & & & 0.164 & $1.31(0.97-1.75)$ & 0.077 & $1.30(0.97-1.75)$ & 0.077 \\
\hline Dominant & $66(36.07)$ & $173(28.69)$ & 0.058 & $1.40(0.99-1.99)$ & 0.058 & $1.40(0.99-1.99)$ & 0.058 \\
\hline Recessive & $176(96.17)$ & $584(96.85)$ & 0.655 & $1.22(0.51-2.96)$ & 0.656 & $1.22(0.51-2.96)$ & 0.655 \\
\hline \multicolumn{8}{|c|}{$R A N$ rs7132224 A>G (HWE=0.231) } \\
\hline AA & $87(47.54)$ & $337(55.89)$ & & 1.00 & & 1.00 & \\
\hline AG & $78(42.62)$ & $220(36.48)$ & & $1.37(0.97-1.95)$ & 0.075 & $1.38(0.97-1.95)$ & 0.074 \\
\hline GG & $18(9.84)$ & $46(7.63)$ & & $1.52(0.84-2.75)$ & 0.170 & $1.52(0.84-2.75)$ & 0.168 \\
\hline Additive & & & 0.132 & $1.28(1.00-1.65)$ & 0.052 & $1.29(1.00-1.65)$ & 0.051 \\
\hline Dominant & $96(52.46)$ & $266(44.11)$ & 0.047 & $1.40(1.003-1.95)$ & 0.048 & $1.40(1.01-1.95)$ & 0.047 \\
\hline Recessive & $165(90.16)$ & $557(92.37)$ & 0.339 & $1.32(0.75-2.34)$ & 0.340 & $1.32(0.75-2.34)$ & 0.338 \\
\hline \multicolumn{8}{|c|}{$R A N$ rs14035 C>T (HWE=0.389) } \\
\hline $\mathrm{CC}$ & $113(61.75)$ & $403(66.83)$ & & 1.00 & & 1.00 & \\
\hline $\mathrm{CT}$ & $63(34.43)$ & $176(29.19)$ & & $1.28(0.90-1.82)$ & 0.178 & $1.28(0.89-1.82)$ & 0.179 \\
\hline TT & $7(3.83)$ & $24(3.98)$ & & $1.04(0.44-2.48)$ & 0.929 & $1.04(0.44-2.47)$ & 0.937 \\
\hline Additive & & & 0.401 & $1.17(0.87-1.55)$ & 0.299 & $1.16(0.87-1.55)$ & 0.302 \\
\hline Dominant & $70(38.25)$ & $200(33.17)$ & 0.205 & $1.25(0.89-1.76)$ & 0.205 & $1.25(0.89-1.76)$ & 0.207 \\
\hline Recessive & $176(96.17)$ & $579(96.02)$ & 0.925 & $0.96(0.41-2.27)$ & 0.926 & $0.96(0.41-2.26)$ & 0.917 \\
\hline \multicolumn{8}{|c|}{ RANBP2 rs2462788 C $>\mathrm{T}(\mathrm{HWE}=0.298)$} \\
\hline $\mathrm{CC}$ & $163(89.07)$ & $554(91.87)$ & & 1.00 & & 1.00 & \\
\hline $\mathrm{CT}$ & $20(10.93)$ & $49(8.13)$ & & $1.39(0.80-2.40)$ & 0.242 & $1.39(0.80-2.41)$ & 0.240 \\
\hline TT & $0(0.00)$ & $0(0.00)$ & & / & / & / & / \\
\hline Additive & & & 0.241 & $1.39(0.80-2.40)$ & 0.242 & $1.39(0.80-2.41)$ & 0.240 \\
\hline Dominant & $20(10.93)$ & $49(8.13)$ & 0.241 & $1.39(0.80-2.40)$ & 0.242 & $1.39(0.80-2.41)$ & 0.240 \\
\hline \multicolumn{8}{|c|}{ Combined effect of risk genotypes for $R A N^{c}$} \\
\hline 0 & $84(45.90)$ & $336(55.72)$ & & 1.00 & & 1.00 & \\
\hline 1 & $28(15.30)$ & $68(11.28)$ & & $1.65(1.00-2.72)$ & 0.051 & $1.65(1.00-2.73)$ & 0.050 \\
\hline 2 & $9(4.92)$ & $26(4.31)$ & & $1.39(0.63-3.07)$ & 0.422 & $1.39(0.63-3.09)$ & 0.415 \\
\hline 3 & $62(33.88)$ & $173(28.69)$ & & $1.43(0.98-2.09)$ & 0.060 & $1.43(0.99-2.09)$ & 0.060 \\
\hline 0 & $84(45.90)$ & $336(55.72)$ & & 1.00 & & 1.00 & \\
\hline $1-3$ & $99(54.10)$ & $267(44.28)$ & 0.020 & $1.48(1.06-2.07)$ & 0.020 & 1.49 (1.07-2.07) & 0.020 \\
\hline
\end{tabular}

OR, odds ratio; $\mathrm{CI}$, confidence interval; HWE, Hardy-Weinberg equilibrium. ${ }^{2} \chi^{2}$ test for genotype distributions between Wilms tumor patients and controls. ${ }^{\circ}$ Adjusted for age and gender. c Risk genotype were with rs56109543 CT/TT, rs7132224 AG/GG and rs14035 CT/TT.

Table 2. Stratification analysis of RAN polymorphisms with Wilms tumor susceptibility

\begin{tabular}{|c|c|c|c|c|c|c|c|c|c|c|c|c|}
\hline \multirow[t]{2}{*}{ Variables } & \multicolumn{2}{|c|}{$\begin{array}{l}\text { rs56109543 } \\
\text { (cases/controls) }\end{array}$} & \multirow[t]{2}{*}{$\operatorname{AOR}(95 \% \mathrm{CI})^{\mathrm{a}}$} & \multirow[t]{2}{*}{$P$ a } & \multicolumn{2}{|c|}{$\begin{array}{l}\text { rs7132224 } \\
\text { (cases/controls) }\end{array}$} & \multirow[t]{2}{*}{$\operatorname{AOR}(95 \% \mathrm{CI})^{a}$} & \multirow[t]{2}{*}{$P$ a } & \multicolumn{2}{|c|}{$\begin{array}{l}\text { Risk genotypes } \\
\text { (cases/controls) }\end{array}$} & \multirow[t]{2}{*}{$\operatorname{AOR}(95 \% \mathrm{CI})^{a}$} & \multirow[t]{2}{*}{$P$ a } \\
\hline & $\mathrm{CC}$ & CT/TT & & & AA & AG/GG & & & 0 & $1-3$ & & \\
\hline \multicolumn{13}{|c|}{ Age, month } \\
\hline$\leq 18$ & $46 / 201$ & $30 / 67$ & 1.98 (1.15-3.38) & 0.013 & $27 / 161$ & $49 / 107$ & $2.80(1.64-4.77)$ & 0.0002 & $27 / 161$ & $49 / 107$ & $2.80(1.64-4.77)$ & 0.0002 \\
\hline$>18$ & $71 / 229$ & $36 / 106$ & $1.10(0.69-1.74)$ & 0.694 & $60 / 176$ & $47 / 159$ & $0.86(0.56-1.34)$ & 0.510 & $57 / 175$ & $50 / 160$ & $0.95(0.62-1.48)$ & 0.830 \\
\hline \multicolumn{13}{|l|}{ Gender } \\
\hline Female & $52 / 189$ & $29 / 78$ & $1.35(0.80-2.28)$ & 0.263 & $38 / 141$ & $43 / 126$ & $1.27(0.77-2.09)$ & 0.350 & $36 / 140$ & $45 / 127$ & $1.38(0.84-2.27)$ & 0.207 \\
\hline Male & $65 / 241$ & $37 / 95$ & $1.45(0.91-2.31)$ & 0.123 & $49 / 196$ & $53 / 140$ & $1.52(0.97-2.36)$ & 0.067 & $48 / 196$ & $54 / 140$ & $1.57(1.01-2.46)$ & 0.046 \\
\hline \multicolumn{13}{|c|}{ Clinical stages } \\
\hline I+II & $43 / 430$ & $24 / 173$ & $1.39(0.82-2.36)$ & 0.226 & $30 / 337$ & $37 / 266$ & $1.56(0.94-2.61)$ & 0.086 & $30 / 336$ & $37 / 267$ & $1.56(0.93-2.59)$ & 0.090 \\
\hline III+IV & $65 / 430$ & $33 / 173$ & $1.26(0.80-1.98)$ & 0.328 & $51 / 337$ & $47 / 266$ & $1.17(0.76-1.80)$ & 0.478 & $48 / 336$ & $50 / 267$ & $1.30(0.85-2.00)$ & 0.226 \\
\hline
\end{tabular}

AOR, adjusted odds ratio; $\mathrm{CI}$, confidence interval. a Adjusted for age and gender, without the corresponding stratify factor. 
Table 3. Stratification analysis of RANBP2 rs2462788 C>T polymorphism with Wilms tumor risk

\begin{tabular}{|c|c|c|c|c|c|c|}
\hline \multirow[t]{2}{*}{ Variables } & \multicolumn{2}{|c|}{$\begin{array}{l}\text { rs2462788 } \\
\text { (cases/controls) }\end{array}$} & \multirow[t]{2}{*}{ OR (95\% CI) } & \multirow[t]{2}{*}{$P$} & \multirow[t]{2}{*}{ AOR $(95 \% \mathrm{CI})^{a}$} & \multirow[t]{2}{*}{$P$ a } \\
\hline & $\mathrm{CC}$ & CT/TT & & & & \\
\hline \multicolumn{7}{|c|}{ Age, month } \\
\hline$\leq 18$ & $63 / 247$ & $13 / 21$ & $2.43(1.15-5.11)$ & 0.020 & $2.43(1.15-5.12)$ & 0.020 \\
\hline$>18$ & $100 / 307$ & $7 / 28$ & $0.77(0.33-1.81)$ & 0.546 & $0.77(0.33-1.82)$ & 0.556 \\
\hline \multicolumn{7}{|l|}{ Gender } \\
\hline Females & $76 / 243$ & $5 / 24$ & $0.67(0.25-1.81)$ & 0.425 & $0.67(0.25-1.81)$ & 0.429 \\
\hline Males & $87 / 311$ & $15 / 25$ & 2.15 (1.08-4.25) & 0.029 & $2.15(1.08-4.25)$ & 0.029 \\
\hline \multicolumn{7}{|c|}{ Clinical stages } \\
\hline I+II & $54 / 554$ & $13 / 49$ & 2.72 (1.39-5.33) & 0.004 & 2.77 (1.41-5.46) & 0.003 \\
\hline III+IV & $93 / 554$ & $5 / 49$ & $0.61(0.24-1.57)$ & 0.302 & $0.62(0.24-1.59)$ & 0.317 \\
\hline
\end{tabular}

$\mathrm{OR}$, odds ratio; $\mathrm{CI}$, confidence interval; $\mathrm{AOR}$, adjusted odds ratio. aAdjusted for age and gender, without the corresponding stratify factor.

Table 4. The frequency of inferred haplotypes of RAN gene based on observed genotypes and their association with the risk of Wilms tumor

\begin{tabular}{|c|c|c|c|c|c|c|}
\hline Haplotypesa & $\begin{array}{l}\text { Cases } \\
(n=366)\end{array}$ & $\begin{array}{l}\text { Controls } \\
(n=1206)\end{array}$ & $\begin{array}{l}\text { Crude OR } \\
(95 \% \mathrm{CI})\end{array}$ & $P$ & $\operatorname{AOR}(95 \% \mathrm{CI})^{\mathrm{b}}$ & $P$ b \\
\hline TTT & $\begin{array}{l}231 \\
(63.11)\end{array}$ & $\begin{array}{l}872 \\
(72.31)\end{array}$ & 1.00 & & 1.00 & \\
\hline TTC & $6(1.64)$ & $1(0.08)$ & $\begin{array}{l}22.65 \\
(2.71-189.07)\end{array}$ & 0.004 & $\begin{array}{l}22.58 \\
(2.68-190.04)\end{array}$ & 0.004 \\
\hline TCT & $38(10.38)$ & $92(7.63)$ & $1.56(1.04-2.34)$ & 0.032 & $1.56(1.04-2.34)$ & 0.031 \\
\hline TCC & $7(1.91)$ & $36(2.99)$ & $0.73(0.32-1.67)$ & 0.461 & $0.74(0.32-1.68)$ & 0.465 \\
\hline CTT & $1(0.27)$ & $0(0.00)$ & / & / & / & / \\
\hline CTC & $0(0.00)$ & $0(0.00)$ & / & / & / & / \\
\hline CCT & $4(1.09)$ & $1(0.08)$ & $\begin{array}{l}15.10 \\
(1.68-135.74)\end{array}$ & 0.015 & $\begin{array}{l}15.22 \\
(1.69-136.97)\end{array}$ & 0.015 \\
\hline $\mathrm{CCC}$ & 79 (21.58) & $\begin{array}{l}204 \\
(16.92)\end{array}$ & 1.46 (1.09-1.97) & 0.012 & 1.46 (1.09-1.97) & 0.012 \\
\hline
\end{tabular}

OR, odds ratio; $\mathrm{CI}$, confidence interval; $\mathrm{AOR}$, adjusted odds ratio. ${ }^{\text {a }}$ The haplotypes order were rs56109543, rs7132224 and rs14035. b Obtained in logistic regression models with adjustment for age and gender.

\section{Discussion}

In this study with 183 cases and 603 controls, significant association was found between the rs7132224 $A>G$ polymorphism and Wilms tumor risk. As far as we know, the current study is the first investigation regarding the association of $R A N$ and RANBP2 gene polymorphisms with Wilms tumor susceptibility.

Previous researches have proved that $R A N$ is involved in multiple cellular processes, including nucleo-cytoplasmic transport, mitotic spindle organization and the formation of nuclear envelope [28-30]. RAN has been shown to be implicated in carcinomas, such as breast cancer and lung cancer, by regulating cell adhesion, migration and invasion [31]. Several researches illustrated that RAN-inhibitory peptide-loaded PEG-PLGA NPs have great potential in curbing cancer through limiting the formation of active forms of RAN [32-34]. In addition, the expression level of RAN was significantly altered in glioblastoma, pancreatic cancer, neuroblastoma, melanoma [35-40].

Recently, there is a growing list of $R A N$ binding proteins, which are molecular targets for inhibiting RAN signaling pathways of in cancer cells, and provide a neoteric approach to the treatment of cancers [27, 41]. RANBP2 known to regulate numerous cellular activities, is reported has an indivisible association with nasopharyngeal carcinoma through interacting with Epac1 [42]. In addition, some investigations have confirmed that RANBP2 is a tumor suppressor [43-45]. Horio et al. found that the transcription of RANBP2 was significantly higher in small cell lung cancer than in other types of lung cancers [46]. Furthermore, RANBP2 was verified to be upregulated in more than half of the multiple myeloma cases[47].

We conducted this study to explore the association of RAN and RANBP2 gene polymorphisms with Wilms tumor susceptibility has not yet been explored. Compared to RAN rs7132224 AA genotype, AG/GG genotypes were found significantly correlated with the risk of Wilms tumor. However, we failed to significant association for other three gene polymorphisms. An early study by Ying et al. indicated that the CC genotype of RAN rs14035 significantly increased the venture of gastric cancer [48]. And the RAN rs14035 CT heterozygote was a protective factor against colorectal cancer for Korean male [49]. However, we failed to find significant association between the rs14035 polymorphism and Wilms tumor, which could be caused by the small sample size. We also testified that carriers of 1-3 risk genotypes were more susceptible to Wilms tumor than those without risk genotype. The stratified analysis exhibited that rs56109543 CT/TT and rs7132224 AG/GG increase the risk of Wilms tumor in children aged $\leq 18$ months. and Carriers of 1-3 risk genotypes have a significant increased susceptibility of Wilms tumor in children aged $\leq 18$ months and male. What's more, the rs2462788 CT/TT in RANBP2 gene increased the chance of Wilms tumor in children aged $\leq 18$ months, male and clinical stage I+II Wilms tumor. So far, no studies have shown a link of $R A N$ rs56109543, RAN rs7132224 and RANBP2 rs2462788 with other tumors, which required more researches.

Although our study is the first investigation about the association of RAN/RANBP2 gene SNPs with Wilms tumor risk, several flaws should be noted. First, the sample size of our study was relatively small. The significant results could be just chance findings, and our results need to be verified by independent cohorts. Secondly, recruitment of participants only from Wenzhou and Guangzhou may cause selection bias; thus the results cannot fully represent other population. Thirdly, mechanisms of how the SNPs modify Wilms tumor susceptibility should be studied. Finally, we only explored the 
effects of genes polymorphisms on tumor susceptibility, but not on tumor development and prognosis.

In conclusion, our data provide evidence that RAN gene rs7132224 $\mathrm{A}>\mathrm{G}$ polymorphism is significantly associated with increased Wilms tumor susceptibility. More comprehensive researches with lager sample size were warranted to validate the association between RAN/RANBP2 gene polymorphisms and Wilms tumor risk.

\section{Abbreviations}

HWE, Hardy-Weinberg equilibrium; OR, odds ratio; $\mathrm{CI}$, confidence interval.

\section{Supplementary Material}

Supplementary figures and tables.

http://www.jcancer.org/v11p0804s1.pdf

\section{Acknowledgments}

This study was funded by grants from the Pearl River S\&T Nova Program of Guangzhou (No: 201710010086), Scientific Research Foundation of Wenzhou (No: 2015Y0492), and Zhejiang Provincial Science and Technology Animal Experimental Platform Project (No: 016C37113).

\section{Competing Interests}

The authors have declared that no competing interest exists.

\section{References}

1. Chen KS, Stroup EK, Budhipramono A, Rakheja D, Nichols-Vinueza D, Xu L, et al. Mutations in microRNA processing genes in Wilms tumors derepress the IGF2 regulator PLAG1. Genes Dev. 2018; 32: 996-1007.

2. Hohenstein P, Hastie ND. LINking microRNAs, kidney development, and Wilms tumors. Genes Dev. 2014; 28: 923-5.

3. Rivera MN, Haber DA. Wilms' tumour: connecting tumorigenesis and organ development in the kidney. Nat Rev Cancer. 2005; 5: 699-712.

4. Tian F, Yourek G, Shi X, Yang Y. The development of Wilms tumor: from WT1 and microRNA to animal models. Biochim Biophys Acta. 2014; 1846: 180-7.

5. Li W, Kessler P, Yeger H, Alami J, Reeve AE, Heathcott R, et al. A gene expression signature for relapse of primary wilms tumors. Cancer Res. 2005; 65: 2592-601.

6. Dome JS, Fernandez CV, Mullen EA, Kalapurakal JA, Geller JI, Huff V, et al. Children's Oncology Group's 2013 blueprint for research: renal tumors. Pediatr Blood Cancer. 2013; 60: 994-1000.

7. Gadd S, Huff V, Walz AL, Ooms A, Armstrong AE, Gerhard DS, et al. A Children's Oncology Group and TARGET initiative exploring the genetic landscape of Wilms tumor. Nat Genet. 2017; 49: 1487-94.

8. Davies R, Moore A, Schedl A, Bratt E, Miyahawa K, Ladomery M, et al. Multiple roles for the Wilms' tumor suppressor, WT1. Cancer Res. 1999; 59: 1747s-50s; discussion 51s.

9. Williams RD, Chagtai T, Alcaide-German M, Apps J, Wegert J, Popov S, et al. Multiple mechanisms of MYCN dysregulation in Wilms tumour. Oncotarget. 2015; 6: 7232-43.

10. Ciceri S, Gamba B, Corbetta P, Mondini P, Terenziani M, Catania S, et al. Genetic and epigenetic analyses guided by high resolution whole-genome SNP array reveals a possible role of CHEK2 in Wilms tumour susceptibility. Oncotarget. 2018; 9: 34079-89.

11. Micale MA, Embrey Bt, Macknis JK, Harper CE, Aughton DJ. Constitutional $560.49 \mathrm{~kb}$ chromosome 2p24.3 duplication including the MYCN gene identified by SNP chromosome microarray analysis in a child with multiple congenital anomalies and bilateral Wilms tumor. Eur J Med Genet. 2016; 59: 618-23.
12. Yu Y, Hu Y, Li K, Chen Z, Zhang H, Zhang L. RECK Gene Polymorphism is Associated with Susceptibility and Prognosis of Wilms' Tumor in Chinese Children. Med Sci Monit. 2015; 21: 1928-33.

13. Kim MK, Min DI, Rabin M, Licht JD. Functional characterization of Wilms tumor-suppressor WTX and tumor-associated mutants. Oncogene. 2011; 30: 832-42.

14. Andrade RC, Cardoso LC, Ferman SE, Faria PS, Seuanez HN, Achatz MI, et al. Association of TP53 polymorphisms on the risk of Wilms tumor. Pediatr Blood Cancer. 2014; 61: 436-41.

15. Royer-Pokora B, Weirich A, Schumacher V, Uschkereit C, Beier M, Leuschner I, et al. Clinical relevance of mutations in the Wilms tumor suppressor 1 gene WT1 and the cadherin-associated protein beta1 gene CTNNB1 for patients with Wilms tumors: results of long-term surveillance of 71 patients from International Society of Pediatric Oncology Study 9/Society for Pediatric Oncology. Cancer. 2008; 113: 1080-9.

16. Fu W, Zhu J, Xiong SW, Jia W, Zhao Z, Zhu SB, et al. BARD1 Gene Polymorphisms Confer Nephroblastoma Susceptibility. EBioMedicine. 2017; 16: $101-5$.

17. Jia W, Deng Z, Zhu J, Fu W, Zhu S, Zhang LY, et al. Association Between HACE1 Gene Polymorphisms and Wilms' Tumor Risk in a Chinese Population. Cancer Invest. 2017; 35: 633-8.

18. Fu W, Liu GC, Zhao Z, Zhu J, Jia W, Zhu SB, et al. The correlation between LIN28B gene potentially functional variants and Wilms tumor susceptibility in Chinese children. J Clin Lab Anal. 2018; 32: e22200.

19. Zhu J, Fu W, Jia W, Xia H, Liu GC, He J. Association between NER Pathway Gene Polymorphisms and Wilms Tumor Risk. Mol Ther Nucleic Acids. 2018; 12: 854-60.

20. Zhu J, Jia W, Wu C, Fu W, Xia H, Liu G, et al. Base Excision Repair Gene Polymorphisms and Wilms Tumor Susceptibility. EBioMedicine. 2018; 33: 88-93.

21. Fu W, Zhuo Z, Hua RX, Fu K, Jia W, Zhu J, et al. Association of KRAS and NRAS gene polymorphisms with Wilms tumor risk: a four-center case-control study. Aging (Albany NY). 2019; 11: 1551-63.

22. de Boor S, Knyphausen P, Kuhlmann N, Wroblowski S, Brenig J, Scislowski L, et al. Small GTP-binding protein Ran is regulated by posttranslational lysine acetylation. Proc Natl Acad Sci U S A. 2015; 112: E3679-88.

23. Oh D, Yu CH, Needleman DJ. Spatial organization of the Ran pathway by microtubules in mitosis. Proc Natl Acad Sci U S A. 2016; 113: 8729-34.

24. Hao Y, Macara IG. Regulation of chromatin binding by a conformational switch in the tail of the Ran exchange factor RCC1. J Cell Biol. 2008; 182: 827-36.

25. Yang Y, Yu H. Partner switching for Ran during the mitosis dance. J Mol Cell Biol. 2018; 10: 89-90.

26. Hashizume C, Kobayashi A, Wong RW. Down-modulation of nucleoporin RanBP2/Nup358 impaired chromosomal alignment and induced mitotic catastrophe. Cell Death Dis. 2013; 4: e854.

27. Wang J, Zhuo Z, Chen M, Zhu J, Zhao J, Zhang J, et al. RAN/RANBP2 polymorphisms and neuroblastoma risk in Chinese children: a three-center case-control study. Aging (Albany NY). 2018; 10: 808-18.

28. Silverman-Gavrila RV, Wilde A. Ran is required before metaphase for spindle assembly and chromosome alignment and after metaphase for chromosome segregation and spindle midbody organization. Mol Biol Cell. 2006; 17: 2069-80.

29. Arnaoutov A, Dasso M. The Ran GTPase regulates kinetochore function. Dev Cell. 2003; 5: 99-111.

30. Tsai MY, Wiese C, Cao K, Martin O, Donovan P, Ruderman J, et al. A Ran signalling pathway mediated by the mitotic kinase Aurora A in spindle assembly. Nat Cell Biol. 2003; 5: 242-8.

31. Yuen HF, Chan KK, Platt-Higgins A, Dakir el H, Matchett KB, Haggag YA, et al. Ran GTPase promotes cancer progression via Met recepto-rmediated downstream signaling. Oncotarget. 2016; 7: 75854-64.

32. Haggag YA, Matchett KB, Falconer RA, Isreb $\mathrm{M}$, Jones J, Faheem A, et al. Novel Ran-RCC1 Inhibitory Peptide-Loaded Nanoparticles Have Anti-Cancer Efficacy In Vitro and In Vivo. Cancers (Basel). 2019; 11: E222.

33. Sheng C, Qiu J, Wang Y, He Z, Wang H, Wang $\mathrm{Q}$, et al. Knockdown of Ran GTPase expression inhibits the proliferation and migration of breast cancer cells. Mol Med Rep. 2018; 18: 157-68.

34. Haggag YA, Matchett KB, Dakir el H, Buchanan P, Osman MA, Elgizawy SA, et al. Nano-encapsulation of a novel anti-Ran-GTPase peptide for blockade of regulator of chromosome condensation 1 (RCC1) function in MDA-MB-231 breast cancer cells. Int J Pharm. 2017; 521: 40-53.

35. Sheng KL, Pridham KJ, Sheng Z, Lamouille S, Varghese RT. Functional Blockade of Small GTPase RAN Inhibits Glioblastoma Cell Viability. Front Oncol. 2018; 8: 662

36. Wang F, Yang L, Shi L, Li Q, Zhang G, Wu J, et al. Nuclear translocation of fibroblast growth factor-2 (FGF2) is regulated by Karyopherin-beta2 and Ran GTPase in human glioblastoma cells. Oncotarget. 2015; 6: 21468-78.

37. Deng L, Shang Y, Guo S, Liu C, Zhou L, Sun Y, et al. Ran GTPase protein promotes metastasis and invasion in pancreatic cancer by deregulating the expression of AR and CXCR4. Cancer Biol Ther. 2014; 15: 1087-93.

38. Saxena S, Gandhi A, Lim PW, Relles D, Sarosiek K, Kang C, et al. RAN GTPase and Osteopontin in Pancreatic Cancer. Pancreat Disord Ther. 2013; 3: 113.

39. Schnepp RW, Khurana P, Attiyeh EF, Raman P, Chodosh SE, Oldridge DA, et al. A LIN28B-RAN-AURKA Signaling Network Promotes Neuroblastoma Tumorigenesis. Cancer Cell. 2015; 28: 599-609. 
40. Caputo E, Wang E, Valentino A, Crispi S, De Giorgi V, Fico A, et al. Ran signaling in melanoma: implications for the development of alternative therapeutic strategies. Cancer Lett. 2015; 357: 286-96.

41. Zhang J, Cong X, Zhaoqiao J, Yang X, Li M, Chen $\mathrm{H}$, et al. Ran binding protein 9 (RanBPM) binds IFN-lambdaR1 in the IFN-lambda signaling pathway. Sci China Life Sci. 2017; 60: 1030-9.

42. Gloerich M, Vliem MJ, Prummel E, Meijer LA, Rensen MG, Rehmann $\mathrm{H}$, et al. The nucleoporin RanBP2 tethers the cAMP effector Epac1 and inhibits its catalytic activity. J Cell Biol. 2011; 193: 1009-20.

43. Navarro MS, Bachant J. RanBP2: a tumor suppressor with a new twist on TopoII, SUMO, and centromeres. Cancer Cell. 2008; 13: 293-5.

44. Kelly E, Harvey J, Brion K, Fletcher J, Slee M. Relapsing necrotising encephalomyelopathy due to RANBP2 mutation. Pract Neurol. 2019; 19: 360-363.

45. Lim JH, Jang S, Park CJ, Cho YU, Lee JH, Lee KH, et al. RANBP2-ALK fusion combined with monosomy 7 in acute myelomonocytic leukemia. Cancer Genet. 2014; 207: 40-5

46. Horio Y, Osada H, Shimizu J, Ogawa S, Hida T, Sekido Y. Relationship of mRNA expressions of RanBP2 and topoisomerase II isoforms to cytotoxicity of amrubicin in human lung cancer cell lines. Cancer Chemother Pharmacol. 2010; 66: 237-43.

47. Felix RS, Colleoni GW, Caballero OL, Yamamoto M, Almeida MS, Andrade $\mathrm{VC}$, et al. SAGE analysis highlights the importance of p53csv, ddx5, mapkapk2 and ranbp2 to multiple myeloma tumorigenesis. Cancer Lett. 2009; 278: 41-8.

48. Xie Y, Wang Y, Zhao Y, Guo Z. Single-nucleotide polymorphisms of microRNA processing machinery genes are associated with risk for gastric cancer. Onco Targets Ther. 2015; 8: 567-71.

49. Cho SH, Ko JJ, Kim JO, Jeon YJ, Yoo JK, Oh J, et al. 3'-UTR Polymorphisms in the MiRNA Machinery Genes DROSHA, DICER1, RAN, and XPO5 Are Associated with Colorectal Cancer Risk in a Korean Population. PLoS One. 2015; 10: e0131125. 